Disclaimer. The opinions expressed in this paper are those of the authors and do not represent the views of government, industry or any NGO.

Conflicts of interest. No authors have any conflict of interest to declare. Dr Spencer received honoraria from Aspen, Adcock Ingram, GSK and MSD in the past 12 months.

Participants. Professors Sharon Cassol and Maureen Taylor; Drs Lynne Webber, Francis Akpan, Andy Beke, Masese Beke, Mariette Botes, Sheila Bowyer, Marieke Brauer, Vivian Cox, Judith Dlamini, Nicollette du Plessis, Hashim Ebrahim, Marcelle Erasmus, Ute Feucht, Allison Glass, Ebrahim Hoosien, Evelyn Kangawasa, Fritz Kinkel, Sim Mayaphi, Daniël Morobadi, Rolando Viani, Marianne Swanepoel, John Sim and Adele Visser; and Messrs Glen Malherbe and Neil Morris.

1. Rajaratnam JK, Marcus JR, Flaxman AD, et al. Neonatal, postneonatal, childhood, and under-5 mortality for 187 countries, 1970-2010: a systematic analysis of progress towards Millennium Development Go 4. Lancet 2010:375:1988-2008.

2. Serenata C. Changes to the ART guidelines - an overview. SA J HIV Med 2010;37:28-30.

3. South African National Department of Health. Clinical guidelines for the management of HIV \& AIDS in adults and adolescents. Pretoria: Department of Health, 2010. www.sanac.org za (accessed AIDS in adults and adolescents. Pretoria: Department of Health, 2010. www.sanac.org.za (accessed
29 May 2010).

4. Antiretroviral treatment of adult HIV infection. 2010. Recommendations of the International AIDS Society - USA panel. JAMA 2010;340(3):321-333.

5. Sterne JA, May M, Costagliola D, et al. When to start consortium. Timing of initiation of antiretroviral therapy in AIDS-free HIV-1-infected patients: a collaborative analysis of 18 HIV cohort studies. Lancet 2009;373(9672):1352-1363

6. Siegfried N, Uthman OA, Rutherford GW. Optimal time for initiation of antiretroviral therapy in asymptomatic, HIV-infected, treatment-naive adults. Cochrane Database of Systematic Reviews 2010, Issue 3. Art. No.:CD008272. DOI:10.1002/14651858.CD008272.pub2.

7. Shelburne SA, Visnegarwala F, Darcourt J, et al. Incidence and risk factors for immune reconstitution inflammatory syndrome during highly active antiretroviral therapy. AIDS 2005;19:399-406.
8. Lichtenstein KA, Armon C, Buchacz K, et al. Initiation of antiretroviral therapy at CD4 cell counts $\geq 350$ cells $/ \mathrm{mm} 3$ does not increase incidence or risk of peripheral neuropathy, anaemia, or renal insufficiency. Acquir Immune Defic Syndr 2008:47(1):27-35.

9. Jonathan U, Armon C, Buchacz K, et al. The HOPS Investigators. Initiation of HAART at higher CD4 9. Jonathan $\mathrm{U}$, Armon $\mathrm{C}$, Buchacz $\mathrm{K}$, et al. The HOPS Investigators. Initiation of HAART at higher CD4
cell counts is associated with a lower frequency of antiretroviral drug resistance mutations at virological cell counts is associated with a lower frequency of antive

10. Bruyand M, Thiebaut R, Lawson-Ayayi S, et al. Role of uncontrolled HIV RNA level and 0. Bruyand $\mathrm{M}$, Thiebaut $\mathrm{R}$, Lawson-Ayayi S, et al. Role of uncontrolled HIV RNA level and
immunodeficiency in the occurrence of malignancy in HIVヌinfected patients during the combination antiretroviral therapy era: Agence Nationale de Recherche sur le Sida (ANRS) CO3 Aquitaine Cohort. Clin Infect Dis 2009;49:1109-1116

11. Moore RD, Keruly JC. CD4+ cell count 6 years after commencement of highly active antiretroviral therapy in persons with sustained virologic suppression. Clin Infect Dis 2007;44:441-446.

12. Badri M, Cleary S, Maartens G, et al. When to initiate highly active antiretroviral therapy in subSaharan Africa? A South African cost-effectiveness study. Antivir Ther 2006;11:63-72.

13. Meyer-Rath G. The cost of the national antiretroviral treatment programme: how big can we go, how much can we save. Presentation at Southern African HIV Clinicians Society, Johannesburg branch meeting, August 2010

14. DART Trial Team. Routine versus clinically driven laboratory monitoring of HIV antiretroviral therapy in Africa (DART): a randomised non-inferiority trial. Lancet 2010;375:123-131.

15. Lyogoba F, Dunn DT, Pillay D, et al. Evolution of drug resistance during 48 weeks of Zidovudine/ Lamivudine/Tenofovir in the absence of real-time viral load monitoring. J Acquir Immune Defic Syndr Lamivudine/Tenofovir in the absence of real-time viral load monitoring. J Acquir Immune Defic Syndr 2010;55:277-283.

6. Gupta RK, Hill A, Sawyer AW, et al. Virological monitoring and resistance to first-line highly active antiretroviral therapy in adults infected with HIV-1 treated under WHO guidelines: a systematic review and meta-analysis. Lancet Infect Dis 2009;9:409-417.

17. Firnhaber C, Reyneke A, Schulze D, et al. The prevalence of hepatitis B co-infection in a South African urban government HIV clinic. S Afr Med J 2008;98:541-544.

8. Soriano V, Rivas $P$, Nunez M. Risks and benefits of using antiretroviral therapy in HIV-infected patients with chronic hepatitis B in developing regions. Clin Infect Dis 2008;47:1486-1489.

19. Zimmermann AE, Pizzoferrato T, Bedford J, et al. Tenofovir-associated acute and chronic kidney disease: A case of multiple drug interactions. Clin Infect Dis 2006;42:283-290.

20. Calmy A, Hirschel B, Cooper DA. Clinical update: adverse effects of antiretroviral therapy. Lancet 2007;370:12-14

21. Knobel H, Guelar A, Montero M, et al. Risk of side effects associated with the use of nevirapine in treatment-naive patients, with respect to gender and CD4 cell count. HIV Med 2009;9(1):14-18.

22. The Antiretroviral Therapy Cohort Collaboration. Life expectancy of individuals on combination antiretroviral therapy in high-income countries: a collaborative analysis of 14 cohort studies. Lancet 2008:372:293-299.

23. Sanne I, Orrell C, Fox MP, et al. Nurse versus doctor management of HIV-infected patients receiving antiretroviral therapy (CIPRA-SA): a randomised non-inferiority trial. Lancet 2010;376:33-40.

\title{
HEALTH POLICY \\ Parenteral artesunate access programme aims at reducing malaria fatality rates in South Africa
}

\author{
E Visser Kift, T Kredo, K I Barnes
}

Parenteral artesunate should be used in preference to quinine for the treatment of severe malaria, given its significant mortality and safety benefits. As the product has not yet been registered for use in South Africa, the Parenteral Artesunate Access Programme has been launched to reduce malaria-related mortality. Severe malaria is a medical emergency that requires prompt treatment to prevent death, which occurs in $10-50 \%$ of patients. ${ }^{1}$ Based on high-quality evidence, the World Health Organization (WHO) now strongly recommends intravenous (IV) artesunate in preference to IV quinine for the treatment of severe malaria in adults. ${ }^{2}$

E Visser-Kift and K I Barnes are based at the Division of Clinical Pharmacology, Department of Medicine, University of Cape Town, where T Kredo was previously employed. T Kredo is currently affiliated to the South African Cochrane Centre, Medical Research Council, Cape Town.

\section{Mortality and safety benefit}

Artesunate, an artemisinin derivative, is highly effective in the treatment of malaria owing to its rapid parasite clearance, broad stage specificity and easy, safe administration compared with quinine.

The South-East Asian Quinine Artesunate Malaria Multicentre Randomised Controlled Trial (SEAQUAMAT) compared parenteral artesunate and quinine in 1461 patients with severe Plasmodium falciparum malaria with death as the primary endpoint. The mortality rate was $15 \%$ in the artesunate arm compared with $22 \%$ in the quinine arm, with an absolute mortality risk reduction between study sites ranging from $5-9 \%$. Therefore, the numbers needed to treat to save one life ranged from $11-20$ patients. Treatment with artesunate was well tolerated, whereas quinine was associated with hypoglycaemia (relative risk (RR) 3.2, $1.3-7.8 ; p=0.009$ ). ${ }^{3}$ A Cochrane systematic review that informed the WHO treatment guidelines favoured the use of IV artesunate over quinine, with a $38 \%$ decrease in the risk of death (RR 0.62 , 95\% confidence interval (CI) $0.51-0.75 ; 1938$ participants, 6 trials). ${ }^{4}$

\section{The challenge}

The Global Health Malaria Elimination Group has set the ambitious goal of eradicating malaria from the planet by $2050 .{ }^{5}$ Together with Namibia, Botswana and Swaziland, South Africa supports the WHO Roll Back Malaria (RBM) initiative in Africa and aims to eliminate 
malaria by 2018. South Africa has made exceptional progress in malaria control over the past decade, decreasing the number of notified malaria cases by $90 \%$, from 61934 in 2000 to 6040 in 2009 (Department of Health Directorate of Malaria and other Vector Borne Diseases, unpublished data). Currently, South Africa has 0.71 malaria cases per 1000 population at risk, and has therefore successfully moved from the effective control to the pre-elimination phase on the malaria elimination continuum. Yet the national malaria case fatality rate has remained essentially unchanged over the last decade and is currently $0.76 \%$, well above the WHO target of $0.5 \%{ }^{6}$

\section{The strategy}

The Parenteral Artesunate Access Programme was launched in South Africa in January 2010. The parenteral artesunate used in all the above clinical trials is manufactured by Guilin Pharmaceuticals in China but is not yet registered for use in South Africa. The Malaria Advisory Group had motivated for a parenteral artesunate access programme since 2007. In June 2009, the Medicines Control Council (MCC) approved the use of parenteral artesunate in patients 12 years and older with severe malaria, on a named-patient basis under Section 21 of the Medicines and Related Substances Act. Regulatory authorities in the UK, USA, the EU, Australia and Canada have similar access programmes for the use of parenteral artesunate. The Parenteral Artesunate Access Programme secretariat is based at the University of Cape Town's Division of Clinical Pharmacology, and central pharmacy at Groote Schuur Hospital.

\section{Ensuring drug quality}

Artesunate was procured from Guilin Pharmaceuticals, who received WHO pre-qualification as operating in compliance with WHO Good Manufacturing Practice (GMP) in November 2010. Importation was authorised by the MCC and quality assurance performed by the MCCapproved Research Institute for Industrial Pharmacy, Potchefstroom University and the Mahidol Oxford Research Unit in Thailand.

\section{Preliminary programme results}

To date, 22 sentinel hospital sites have been enrolled in the access programme, trained and provided with parenteral artesunate stock. For each eligible patient, informed consent and MCC approval must be obtained, which is facilitated by the Parenteral Artesunate Access Programme secretariat. Case record forms are provided to encourage optimal assessment and monitoring of patients with severe malaria. Strict drug accountability is needed for the MCC to authorise ongoing access to parenteral artesunate.

To date, 92 patients ( 65 male) with a median age of 36 years (range 14 - 79 years) at 16 hospitals in 6 provinces have received IV artesunate. Almost half (46\%) of these patients were treated in the malaria-risk areas of Limpopo, Mpumalanga and KwaZulu-Natal, $33 \%$ in the Western Cape and $20 \%$ in Gauteng. This distribution of drug use is surprising as the largest number of malaria cases is reported in Gauteng, ${ }^{6}$ followed by Limpopo and Mpumalanga (Department of Health Directorate of Malaria and other Vector Borne Diseases, unpublished data).

Of the 78 patients for whom we received reports on treatment outcome, 63 were well on discharge, 9 were not fully recovered (renal dysfunction or co-morbidities persisting) and 5 (6.4\%) had died. There was a significant difference in the median (IQR) number of presenting complications between those who died and survived (5 $(4-6)$ v. $3(2-4) ; p=0.03)$. Fig. 1 shows the features of severe malaria present at diagnosis. Appropriate laboratory investigations were not recorded for all patients. Of the recorded complications, acidosis $(p<0.0001)$, hyperlactataemia $(p=0.007)$ and visible jaundice $(p=0.04)$

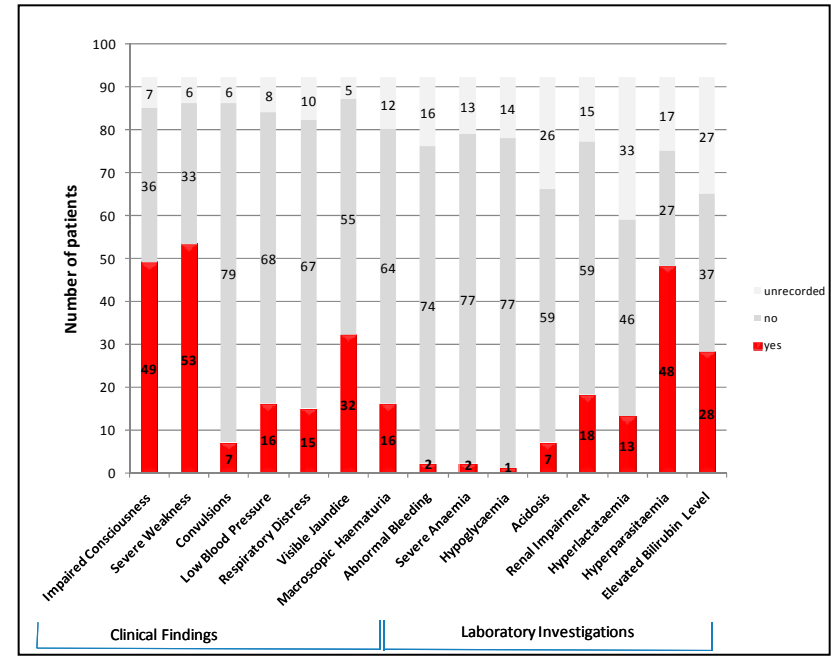

Fig. 1. Features of severe malaria $(\mathrm{N}=92)$.

were associated with death. No adverse events or serious adverse events have been reported to date.

\section{The way forward}

The preliminary data describe the effective and safe use of IV artesunate in South African adults, which supports continued Section 21 access until registered for use. Results recently released in the Lancet show that similar mortality reductions can be achieved in African children, with a relative mortality reduction of $22.5 \%$ (95\% CI $8.1-36.9 ; p=0.0231$ ) and a corresponding number needed to treat of 41 children (95\% CI 25 - 112) to prevent one death. ${ }^{7}$ Based on these findings, an application for extending the parenteral artesunate access programme to children was recently approved by the MCC.

Success in reducing malaria-related morbidity and mortality in South Africa requires that increasing numbers of adult and paediatric severe malaria patients access the best available treatment. Parenteral artesunate is currently only available via the special access initiative. Hospitals interested in participating in this access programme can contact the corresponding author or secretariat (Marilyn Solomons, e-mail marilyn. solomons@uct.ac.za, phone 021406 6355) for further details.

The authors gratefully acknowledge the guidance and support provided by the Medicines Control Council, Department of Health Directorate of Malaria and other Vector Borne Diseases, National Malaria Advisory Group, Provincial Malaria Control Programme Managers, participating hospital staff, Lesley Workman (Data Management) and the Parenteral Access Programme secretariat (Marilyn Solomons and Faikah Simons).

\footnotetext{
Day N, Dondorp AM. The management of patients with severe malaria. Am J Trop Med Hyg 2007;77(6):29-35.

2. World Health Organization Guidelines for the Treatment of Malaria, 2nd ed. Geneva: World Health Organization, 2006. http://whqlibdoc.who.int/publications/2010/9789241547925_eng.pdf (accessed 29 December 2010)

3. South East Asian Quinine Artesunate Malaria Trial (SEAQUAMAT) group. Artesunate versus quinine for treatment of severe falciparum malaria: a randomized trial. Lancet 2005;366:717-725.

4. Jones KL, Donegan S, Lalloo DG. Artesunate versus quinine for treating severe malaria. Cochrane Database of Systematic Reviews 2007, Issue 4. Art. No.: CD005967. DOI:10.1002/14651858.CD005967. pub2. (review update 2010, Issue 1.)

5. Feachem RGA, Malaria Elimination Group. Shrinking the Malaria Map: A Guide on Malaria Elimination for Policy Makers. http://www.malariaeliminationgroup.org/sites/default/files/fileuploads/ AGuideonMalariaEliminationforPolicyMakers.pdf (accessed 29 December 2010).

6. Weber IB, Baker L, Mnyaluza J, et al. The burden of imported malaria in Gauteng Province. S Afr Med Jeber IB, Baker L,

7. Dondorp AM, Fanello CI, Hendriksen ICE, et al. Artesunate versus quinine in the treatment of severe falciparum malaria in African children (AQUAMAT): an open-label, randomized trial. Lancet 2010;376:1647-1657.
}

Accepted 21 January 2011. 